\title{
Sensitivity of top-down CO source estimates to the modeled vertical structure in atmospheric CO
}

\author{
Z. Jiang ${ }^{1, *}$, D. B. A. Jones ${ }^{1,2}$, H. M. Worden ${ }^{3}$, and D. K. Henze ${ }^{4}$ \\ ${ }^{1}$ Department of Physics, University of Toronto, Toronto, ON, Canada \\ ${ }^{2}$ JIFRESSE, University of California, Los Angeles, Los Angeles, CA, USA \\ ${ }^{3}$ National Center for Atmospheric Research, Boulder, CO, USA \\ ${ }^{4}$ Department of Mechanical Engineering, University of Colorado Boulder, Boulder, CO, USA \\ *now at: Jet Propulsion Laboratory, California Institute of Technology, Pasadena CA, USA
}

Correspondence to: Z. Jiang (zhe.jiang @jpl.nasa.gov)

Received: 8 August 2014 - Published in Atmos. Chem. Phys. Discuss.: 8 September 2014

Revised: 5 January 2015 - Accepted: 8 January 2015 - Published: 11 February 2015

\begin{abstract}
We assessed the sensitivity of regional CO source estimates to the modeled vertical CO distribution by assimilating multi-spectral MOPITT (Measurements of Pollution In The Troposphere) V5J CO retrievals with the GEOSChem model. We compared the source estimates obtained by assimilating the $\mathrm{CO}$ profiles and the surface layer retrievals from June 2004 to May 2005. Because the surface layer retrievals are less sensitive to $\mathrm{CO}$ in the free troposphere, it is expected that they should provide constraints in the $\mathrm{CO}$ source estimates that are less sensitive to the vertical structure of $\mathrm{CO}$ in the free troposphere. The inferred source estimates all suggest a reduction in $\mathrm{CO}$ emissions in the tropics and subtropics, and an increase in the extratropics over the a priori estimates. The tropical decreases were particularly pronounced for regions where the biogenic source of $\mathrm{CO}$ was dominant, suggesting an overestimate of the a priori isoprene source of CO in the model. We found that the differences between the regional source estimates inferred from the profile and surface layer retrievals for 2004-2005 were small, generally less than $10 \%$ for the main continental regions, except for estimates for southern Asia, North America, and Europe. Because of discrepancies in convective transport in the model, the CO source estimates for India and southeastern Asia inferred from the $\mathrm{CO}$ profiles were significantly higher than those estimated from the surface layer retrievals during June-August 2004. On the other hand, the profile inversion underestimated the $\mathrm{CO}$ emissions from North America and Europe compared to the assimilation of the surface layer retrievals. We showed that vertical transport of air from
\end{abstract}

the North American and European boundary layers is slower than from other continental regions, and thus air in the free troposphere from North America and Europe in the model is more chemically aged, which could explain the discrepancy between the source estimates inferred from the profile and surface layer retrievals. We also examined the impact of the $\mathrm{OH}$ distribution on the source estimates and found that the discrepancies between the source estimates obtained with two $\mathrm{OH}$ fields were larger when using the profile data, which is consistent with greater sensitivity to the more chemically aged air in the free troposphere. Our findings indicate that regional $\mathrm{CO}$ source estimates are sensitive to the vertical $\mathrm{CO}$ structure. They suggest that diagnostics to assess the age of air from the continental source regions should help interpret the results from $\mathrm{CO}$ source inversions. Our results also suggest that assimilating a broader range of composition measurements to provide better constraint on tropospheric $\mathrm{OH}$ and the biogenic sources of $\mathrm{CO}$ is essential for reliable quantification of the regional $\mathrm{CO}$ budget.

\section{Introduction}

The emissions of greenhouse gases and other atmospheric pollutants have been significantly increased since the industrial revolution. Their influences on atmospheric chemical composition, local air quality and climate are the subject of increasing numbers of studies. In this context, inverse modeling has been widely used to provide better understanding of 
the emissions of these atmospheric constituents. In particular, in the past decade there has been expanded use of inverse modeling to better quantify the emissions of atmospheric $\mathrm{CO}$ (e.g., Pétron et al., 2004; Heald et al., 2004; Arellano and Hess, 2006; Jones et al., 2009; Kopacz et al., 2010; FortemsCheiney et al., 2011; Gonzi et al., 2011). Tropospheric CO is produced from incomplete combustion and is a byproduct of oxidation of hydrocarbons. As the primary sink of $\mathrm{OH}$, tropospheric $\mathrm{CO}$ has significant influence on the oxidative capacity of the atmosphere. The lifetime of tropospheric $\mathrm{CO}$ is a few months, which is long enough to track within intercontinental scale pollution plumes but short enough to provide strong signals over background distribution (Jiang et al., 2011). Previous studies (Palmer et al., 2006; Wang et al., 2009) have demonstrated that $\mathrm{CO}$ can be included in the inverse analyses of $\mathrm{CO}_{2}$ sources and sinks to reduce the influence of model transport errors.

Remote sensing from space-based instruments provide valuable global observational coverage to enable us to better constrain CO emissions. There are now several satellite sensors from which abundances of $\mathrm{CO}$ in the troposphere have been retrieved using measurement of thermal infrared (TIR) radiation near $4.7 \mu \mathrm{m}$ : MOPITT (Measurements of Pollution In The Troposphere), on EOS-Terra, launched December 1999 (Deeter et al., 2003); AIRS (Atmospheric InfraRed Sounder), on EOS-Aqua, launched May, 2002 (Warner et al., 2007); TES, (Tropospheric Emission Spectrometer) on EOSAura, launched July, 2004 (Luo et al., 2007); and IASI (Infrared Atmospheric Sounding Interferometer), on METOPA, launched October, 2006 (George et al., 2009). The TIR radiances are sensitive to $\mathrm{CO}$ concentrations from the middle to the upper troposphere. The lack of global observations of $\mathrm{CO}$ near the surface has implications for the use of inverse modeling to quantify $\mathrm{CO}$ emissions, because the modeled $\mathrm{CO}$ distribution in the free troposphere is affected by discrepancies in the parameterization of convective transport in models (e.g., Ott et al., 2009), the simulated chemical sink of CO (e.g., Jiang et al., 2011), and long-range transport (e.g., Arellano and Hess, 2006; Jiang et al., 2013).

The multi-spectral MOPITT version 5 CO product (V5J, where $\mathrm{J}$ indicates joint retrievals) are the first retrievals to exploit simultaneous near infrared (NIR) and TIR measurement to provide greater sensitivity to $\mathrm{CO}$ in the lower troposphere over land (Deeter et al., 2011). Recently, Jiang et al. (2013) showed that lower tropospheric MOPITT V5J CO retrievals can be used to study the influence of convective transport error on $\mathrm{CO}$ source estimates. They compared the $\mathrm{CO}$ source estimates in June-August 2006, inferred from MOPITT surface layer retrievals, the profile retrievals, and the column amounts. They found that there were large discrepancies in the inferred source estimates obtained with the surface layer and profile retrievals in Asian monsoon regions where strong emissions are co-located with significant vertical mass flux due to convection. The discrepancies in the CO source estimates were also used to assess the impact of vertical trans- port error on the $\mathrm{CH}_{4}$ emission estimates from Indonesian peat fires in fall 2006, estimated from $\mathrm{TES} \mathrm{CH}_{4}$ observations (Worden et al., 2013).

The study by Jiang et al. (2013) was carried only for summer 2006 and focused mainly on discrepancies in convective transport. The work presented here complements and extends that analysis. Reflecting its long lifetime, $\mathrm{CO}$ is destroyed mainly in the free troposphere rather than in the boundary layer. Thus, free tropospheric CO will be more susceptible to discrepancies in $\mathrm{OH}$ and in long-range transport. One way to mitigate the potential impact of discrepancies in transport and $\mathrm{OH}$ on $\mathrm{CO}$ inversion analyses is to use surface observations near the $\mathrm{CO}$ source regions. However, the current surface-observing network is sparse, whereas MOPITT provides significantly greater observational coverage. Therefore, we focus here on the use of the surface layer retrievals from MOPITT for inverse modeling CO sources. We expect that the source estimates inferred from the surface layer retrievals will be less sensitive to errors in $\mathrm{OH}$ and model transport. We estimate and compare monthly CO source estimates for June 2004 to May 2005 using MOPITT tropospheric profiles and surface layer retrievals to observe the influence of the $\mathrm{OH}$ distribution and the vertical structure in $\mathrm{CO}$, as observed by MOPITT, on the inferred source estimates. The updated global CO distributions will be used as boundary conditions in our companion paper to constrain the North America CO emission at a horizontal resolution of $0.5^{\circ} \times 0.67^{\circ}$ (Jiang et al., 2015). The objective of that study is to assess the extent to which we can further reduce the impact of model transport and chemistry errors on $\mathrm{CO}$ source estimates in a regional inverse modeling context.

This paper is organized as follows: in Sect. 2 we describe the MOPITT instruments and the GEOS-Chem model used in this work. In Sect. 3 we outline the inverse method. We then discuss the annual and seasonal variations of the estimated $\mathrm{CO}$ emissions in Sect. 4. The discrepancies in the $\mathrm{CO}$ source estimates are interpreted in the context of the $\mathrm{CO}$ vertical structure and the $\mathrm{OH}$ distribution. Our conclusions follow in Sect. 5. In Appendix A we present the results of an indirect validation of the MOPITT data that was conducted to guide the filtering of the data used in the assimilation, and in Appendix B we have included a discussion of the optimization scheme used in the assimilation.

\section{Observations and model}

\subsection{MOPITT}

The MOPITT instrument was launched on the Terra spacecraft on 18 December 1999. The satellite is in a sunsynchronous polar orbit of $705 \mathrm{~km}$ and crosses the equator at 10:30 LT (local time). With a footprint of $22 \mathrm{~km} \times 22 \mathrm{~km}$, the instrument makes measurements in a $612 \mathrm{~km}$ cross-track scan that provides global coverage every 3 days. The MO- 
PITT data used here were obtained from the joint retrieval of CO from TIR $(4.7 \mu \mathrm{m})$ and NIR $(2.3 \mu \mathrm{m})$ radiances using an optimal estimation approach (Worden et al., 2010; Deeter et al., 2011). The retrieved volume mixing ratios (VMRs) are reported as layer averages on 10 pressure levels (surface, 900 , $800,700,600,500,400,300,200$ and $100 \mathrm{hPa}$ ) and the relationship between the retrieved $\mathrm{CO}$ profile and the true atmospheric state can be expressed as

$\hat{z}=\mathbf{Z}_{\mathrm{a}}+\mathbf{A}\left(\mathbf{Z}-\mathbf{Z}_{\mathrm{a}}\right)+\mathbf{G} \varepsilon$,

where $\mathbf{Z}_{\mathrm{a}}$ is the MOPITT a priori CO profile (expressed as $\log (\mathrm{VMR})$ ), $\mathbf{Z}$ is the true atmospheric state (also as $\log (\mathrm{VMR})), \mathbf{G} \varepsilon$ describes the retrieval error, and $\mathbf{A}=\partial \hat{z} / \partial \mathbf{z}$ is the MOPITT averaging kernel matrix, which gives the sensitivity of the retrieval to the actual $\mathrm{CO}$ in the atmosphere. The MOPITT V5 data have been evaluated by Deeter et al. $(2012,2013)$ using aircraft measurements from the National Oceanic and Atmospheric Administration (NOAA). For the V5J multi-spectral retrievals, they found a small positive bias of $2.7 \%$ at the surface and a much larger positive bias of $14 \%$ at $200 \mathrm{hPa}$. As a result of the high bias in the upper troposphere, in our analysis we do not use the retrievals at altitudes above $200 \mathrm{hPa}$. We conduced an indirect validation of the MOPITT V5J data (see Appendix A) using NOAA Global Monitoring Division (GMD) in situ observations, which suggested that there is a high-latitude positive bias in the MOPITT data, possibly associated with the lower degrees-of-freedom-for-signal (DFS) at higher latitudes. Consequently, in this work, we omitted MOPITT data that are polarward of $40^{\circ}$ over oceans and $52^{\circ}$ over land.

\subsection{GEOS-Chem}

The GEOS-Chem global chemical transport model (CTM) [http://www.geos-chem.org] is driven by assimilated meteorological fields from the NASA Goddard Earth Observing System (GEOS-5) at the Global Modeling and data Assimilation Office. We use version v34 of the GEOS-Chem adjoint, which is based on v8-02-01 of the forward GEOSChem model, with relevant updates through v9-01-01. Our analysis is conducted at a horizontal resolution of $4^{\circ} \times 5^{\circ}$ and employs the CO-only simulation in GEOS-Chem, which uses archived monthly $\mathrm{OH}$ fields from the full chemistry simulation. The standard $\mathrm{OH}$ fields used in this work are from GEOS-Chem version v5-07-08, with a global annual mean $\mathrm{OH}$ concentration of $0.99 \times 10^{6} \mathrm{molec} \mathrm{cm}^{-3}$ (Evans and Jacob, 2005). We use this as our standard $\mathrm{OH}$ field to facilitate comparison of our results with those of Kopacz et al. (2010). We also conduct a sensitivity analysis using $\mathrm{OH}$ fields from the full chemistry simulation of v34 of the adjoint model, run in forward mode. This simulation produces a global annual mean $\mathrm{OH}$ concentration of $1.24 \times 10^{6} \mathrm{molec} \mathrm{cm}^{-3}$.

The anthropogenic emission inventories are identical to those used in Jiang et al. (2013). Anthropogenic emissions are from EDGAR 3.2FT2000 (Olivier and Berdowski, 2001), but are replaced by the following regional emission inventories: the US Environmental Protection Agency National Emission Inventory (NEI) for 2005 in North America, the criteria air contaminants (CAC) inventory for Canada, the Big Bend Regional Aerosol and Visibility Observational (BRAVO) Study Emissions Inventory for Mexico (Kuhns et al., 2003), the Cooperative Programme for Monitoring and Evaluation of the Long-range Transmission of Air Pollutants in Europe (EMEP) inventory for Europe in 2000 (Vestreng and Klein, 2002) and the INTEX-B Asia emissions inventory for 2006 (Zhang et al., 2009). Biomass burning emissions are based on the Global Fire Emission Database (GFED3), with a $3 \mathrm{~h}$ temporal resolution (van der Werf et al., 2010). Additional $\mathrm{CO}$ sources come from oxidation of methane and biogenic volatile organic compounds (VOCs,) as described in previous studies (Kopacz et al., 2010; Jiang et al., 2013). The biogenic emissions are simulated using the Model of Emissions of Gases and Aerosols from Nature, version 2.0 (MEGANv2.0) (Guenther et al., 2006). The distribution of the annual mean CO emissions for June 2004 to May 2005 is shown in Fig. 1. The annual global sources are $928 \mathrm{Tg} \mathrm{CO}$ from fossil fuel, biofuel and biomass burning, $661 \mathrm{Tg}$ CO from the oxidation of biogenic NMVOCs (nonmethane volatile organic compounds), and $884 \mathrm{Tg}$ CO from the oxidation of $\mathrm{CH}_{4}$.

\section{Inversion approach}

We use the 4-dimensional variational (4-D-var) data assimilation system in GEOS-Chem (e.g., Henze et al., 2007; Kopacz et al., 2009, 2010; Singh et al., 2011; Jiang et al., 2011, 2013; Parrington et al., 2012) to estimate the CO sources. Details of the 4-D-var scheme are given in Henze et al. (2007) and Kopacz et al. (2009, 2010). In this approach, we minimize the cost function of the form:

$$
\begin{aligned}
J(\mathbf{x}) & =\sum_{i=1}^{N}\left(\boldsymbol{F}_{i}(\boldsymbol{x})-z_{i}\right)^{\mathbf{T}} \mathbf{S}_{\Sigma}^{-\mathbf{1}}\left(\boldsymbol{F}_{i}(\boldsymbol{x})-\mathbf{z}_{i}\right) \\
& +\left(\boldsymbol{x}-\boldsymbol{x}_{\mathbf{a}}\right)^{\mathbf{T}} \mathbf{S}_{\mathbf{a}}^{-\mathbf{1}}\left(\boldsymbol{x}-\boldsymbol{x}_{\mathbf{a}}\right),
\end{aligned}
$$

where $\boldsymbol{x}$ is the state vector of $\mathrm{CO}$ emissions, $N$ is the number of MOPITT observations that are distributed in time over the assimilation period, $z_{i}$ is a given MOPITT profile (or surface level retrieval), and $\boldsymbol{F}(\boldsymbol{x})$ is the forward model which represents the transport and chemistry of CO in the GEOS-Chem model and accounts for the vertical smoothing of the MOPITT retrieval,

$\mathbf{F}_{i}(\mathbf{x})=\mathbf{z}_{\mathrm{a}}+\mathbf{A}\left(\mathbf{H}_{i}(\mathbf{x})-\mathbf{z}_{\mathrm{a}}\right)$

Here $z_{\mathrm{a}}$ and $\mathbf{A}$ are the MOPITT a priori profile and averaging kernel, respectively, introduced in Eq. (1), and $\mathbf{H}_{i}(\boldsymbol{x})$ is the GEOS-Chem profile of $\mathrm{CO}$ at the MOPITT observation location and time. The definition of the cost function assumes that the distribution of the errors for both the state vector $\boldsymbol{x}$ and 




Figure 1. Annual mean CO emissions from combustion sources and the oxidation of biogenic NMVOC and $\mathrm{CH}_{4}$, averaged from June 2004 to May 2005. The unit is $10^{12}$ molec $\mathrm{cm}^{-2} \mathrm{~s}^{-1}$. The continental domains are defined with black boxes. The sub-continental domains in North America (US, Mexico, Alaska and Canada) are separated based on the country boundaries.

the a priori constraint on the $\mathrm{CO}$ emissions $\mathbf{x}_{\mathrm{a}}$ are Gaussian, and these errors are given by $\mathbf{S}_{\Sigma}$, the observational error covariance matrix, and $\mathbf{S}_{\mathbf{a}}$, the a priori error covariance matrix, respectively. Minimization of the cost function provides the a posteriori $\mathrm{CO}$ emissions $\hat{\boldsymbol{x}}$, corresponding to the maximum of the conditional probability density function $(P(\mathbf{x} \mid \mathbf{y}))$, with the a posteriori error covariance matrix $\hat{\boldsymbol{S}}$. However, because the 4-D-var optimization scheme does not store the full Hessian matrix, it is difficult to construct the a posteriori error covariance matrix, which is the inverse of the Hessian. Details of the optimization approach are given in Appendix B.

We employ a similar procedure for data processing and quality control as in our previous study, Jiang et al. (2013). Since MOPITT V5J CO retrievals have a positive bias at high altitudes (Deeter et al., 2013), our analysis is restricted to CO retrievals below $200 \mathrm{hPa}$. Following Jiang et al. (2013), we also reject MOPITT data with CO column amounts less than $5 \times 10^{17}$ molec $\mathrm{cm}^{-2}$ and use only daytime data. The threshold of $5 \times 10^{17} \mathrm{molec}^{-2}$ was selected to prevent unrealistically low CO columns from adversely impacting the inversion analyses.

The observation error $\mathbf{S}_{\Sigma}$ represents a sum of the retrieval errors, representativeness errors, and random model errors. Using the relative residual error (RRE) approach (Palmer et al., 2003; Heald et al., 2004), which assumes that the mean differences between the model and observations are due to discrepancies in the emissions while the residual reflects the observation error, Kopacz et al. (2010) estimated that the observation errors for the MOPITT columns are $10-30 \%$. Although the RRE approach does not account for systematic model errors, it provides a possible estimate of the random component of the observation errors. Accurately characterizing the systematic errors (in the model and observations) is a challenge. Keller et al. (2015) have assimilated MOPITT V5J data using a weak-constraint 4-D-var scheme to characterize the systematic component of the observation error. Their results suggest that the weak-constraint 4-D-var is a promising approach for accounting for systematic errors, but it is still challenging. In the absence of meaningful information about the systematic errors in the model for the period considered here, we do not account for systematic errors in minimizing the cost function. Following Jiang et al. (2011, 2013), we assume a uniform observation error of $20 \%$. Our assumed $20 \%$ error likely overestimates the observation error in the upper troposphere and underestimates it near the surface.

As described in Jiang et al. (2013), we combine the combustion $\mathrm{CO}$ sources (fossil fuel, biofuel and biomass burning) with the $\mathrm{CO}$ from the oxidation of biogenic NMVOCs and solve for the total $\mathrm{CO}$ emissions in each grid box, assuming a $50 \%$ uniform a priori error and that the errors are uncorrelated. We optimize the source of $\mathrm{CO}$ from the oxidation of methane separately as an aggregated global source, assuming an a priori uncertainty of $25 \%$. As in Jiang et al. (2013), we produce initial conditions at the beginning of each monthly assimilation window by assimilating MOPITT V5J data using a sequential sub-optimal Kalman filter (Parrington et al., 2008). For the results presented here, the Kalman filter assimilation was carried out from 1 January 2004 to 1 May 2005 in order to optimize the CO distribution, which was archived at the beginning of each month. 
In the monthly inversion using the 4-D-var system, the optimized CO distribution from the Kalman filter was read at the beginning of each month to obtain initial conditions. Consequently, the initial conditions for the model simulation are independent of the inverse analyses. Although we use a 1month assimilation window, it is possible that a longer window of 2 or 3 months would lead to greater constraints on the $\mathrm{CO}$ source estimates. However, as we will show below, the inversion is sensitive to the specified $\mathrm{OH}$ distribution and thus with a longer assimilation window would be more susceptible to discrepancies in the CO chemical sink.

\section{Results and discussion}

\subsection{CO source estimates for June 2004-May 2005}

Figure $2 \mathrm{a}$ and $\mathrm{f}$ show the annual mean emission scaling factors for June 2004 to May 2005, obtained using the MOPITT surface layer and profile retrievals, respectively. Both analyses suggest that $\mathrm{CO}$ emissions in the tropics should be reduced, whereas the emissions in middle and high latitudes should be increased. However, as shown in Fig. 2k, the a posteriori scaling factors from profile inversion is higher in India and southeastern Asia. As discussed in Jiang et al. (2013), these discrepancies over India and southeastern Asia are likely due to model errors in convection transport. The profile inversion also produces larger emissions in parts of tropical Africa and northern South America. In general, however, the a posteriori emissions from the profile inversion are lower than those obtained from the surface layer inversion, particularly at middle and high latitudes.

Table 1 shows the annual mean regional CO emissions from June 2004 to May 2005, inferred from the surface layer and profile retrievals. In this work, only the total $\mathrm{CO}$ emission is optimized in each grid box, but because the different $\mathrm{CO}$ source types have different spatial and temporal distributions, we apply the scaling factors in each grid box to each source type, which can provide useful information on the individual source types. As shown in Table 1, the emission reductions in the tropics and subtropics reflect large reductions in the biogenic source of $\mathrm{CO}$, suggesting that our a priori biogenic emissions are too high. For example, in South America, with the profile inversion the biogenic source was reduced by $32 \%$, whereas the combustion source was reduced by $13 \%$. In northern Africa the biogenic source was reduced by $26 \%$ and the combustion source was reduced by $20 \%$ with the profile inversion. In the 48 contiguous United States the biogenic source was reduced by $31 \%$, whereas the combustion source was increased by $5 \%$. The reductions in the biogenic emissions were smaller in the surface layer inversion, but were still large for South America and northern Africa, 27 and $28 \%$, respectively. We note that although there are large differences between the regional source estimates inferred from the profile and surface layer retrievals, the global to- tal a posteriori $\mathrm{CO}$ emissions estimated from the two sets of retrievals are similar, 1513 and $1555 \mathrm{Tg} \mathrm{CO}$, respectively.

The seasonal mean scaling factors are shown in Fig. 2. The main seasonal feature in the figure is that the inversions tend to decrease $\mathrm{CO}$ emission in the summer hemisphere and increase them in the winter hemisphere, with the profile inversion producing larger reductions ( $2 \mathrm{~b}$ and $2 \mathrm{~g}$ ) and smaller increases (Fig. 2d and i). Consequently, the differences between the scaling factors from the surface and profile inversions are smaller in winter. This pattern is consistent with an overestimate of isoprene emissions and a possible underestimate of wintertime fossil fuel combustion (Stein et al., 2014). The overestimate of biogenic emissions in GEOSChem by MEGANv2.0 has been reported by previous studies (Barkley et al., 2008; Millet et al., 2008; Liu et al., 2010). Millet et al. (2008) found that North American isoprene emissions estimated by MEGAN were greater than those inferred from observations of formaldehyde (HCHO) from the Ozone Monitoring Instrument (OMI) by as much as $23 \%$. Liu et al. (2010) used a newer version of MEGAN, version 2.1, which simulates lower isoprene emissions than version 2.0 (which is employed in our analysis), and found that it also produced an overestimate of $\mathrm{CO}$ from isoprene oxidation, particularly in eastern South America. Marais et al. (2014) found that MEGANv2.1 overestimated African isoprene emissions for $2005-2009$ by $26 \%$ relative to those inferred from OMI data, primarily over the equatorial forests and the northern savannas.

Figure 3 shows the time series of the monthly mean source estimates for the 48 contiguous United States, Europe, eastern Asia, and India/southeastern Asia. For India/southeastern Asia, the dominant source of $\mathrm{CO}$ is biomass burning from Indonesia, which peaks in August-October, and from southeastern Asia, which peaks in February-April. For the other regions, combustion of fossil fuels and biofuels provides the main annual source of $\mathrm{CO}$. As we noted above, the tendency is for the inverse model to reduce the emissions in summer and increase them in winter, particularly in the United States and eastern Asia. In the profile inversion, the North American combustion emissions were reduced by about a factor of 2 in July and August 2004, whereas they were increased by $48 \%$ in January-March 2005. The summertime reduction of the North American combustion emissions was smaller than that obtained with the surface layer retrievals, whereas the wintertime increase was similar in both inversions. In Asia, both inversions produced comparable summertime reductions and wintertime increases in the combustion emissions, with the emission estimates from the profile inversion being slightly lower in summer and higher in winter. The seasonality of the European source estimates obtained from the surface layer retrievals was much less pronounced than that obtained for North America and Asia, and was consistently higher than those obtained from the profile inversion. 
Table 1. Annual total CO emission in different regions, from June 2004 to May 2005, constrained by MOPITT surface level and tropospheric profile retrievals. The relative difference on total (combustion + oxidation from biogenic VOCs) CO emission estimates is calculated by $2 \cdot\left(\mathrm{CO} \_\right.$surface-CO_profile) / (CO_surface $+\mathrm{CO} \_$profile). The region definition is shown in Fig. 1 .

\begin{tabular}{|c|c|c|c|c|c|c|c|c|c|}
\hline \multirow[b]{2}{*}{ Regions } & \multicolumn{4}{|c|}{ A Priori estimates $\left(\right.$ Tg year $\left.^{-1}\right)$} & \multicolumn{2}{|c|}{ Surface level inversion } & \multicolumn{2}{|c|}{ Profile inversion } & \multirow{2}{*}{$\begin{array}{r}\text { Relative differece } \\
\text { between surface and } \\
\text { profile inversion }\end{array}$} \\
\hline & $\begin{array}{r}\text { Fossil fuel } \\
+ \text { biofuel }\end{array}$ & $\begin{array}{r}\text { Biomass } \\
\text { burning }\end{array}$ & $\begin{array}{r}\text { Total of } \\
\text { combustion }\end{array}$ & $\begin{array}{l}\text { Oxidation from } \\
\text { biogenic VOCs }\end{array}$ & $\begin{array}{r}\text { Total of } \\
\text { Combustion }\end{array}$ & $\begin{array}{l}\text { Oxidation from } \\
\text { biogenic VOCs }\end{array}$ & $\begin{array}{r}\text { Total of } \\
\text { combustion }\end{array}$ & $\begin{array}{l}\text { Oxidation from } \\
\text { biogenic VOCs }\end{array}$ & \\
\hline US 48 states & 94 & 1 & 95 & 44 & 112 & 38 & 100 & 31 & $13 \%$ \\
\hline Alaska and Canada & 4 & 34 & 38 & 9 & 44 & 9 & 38 & 8 & $15 \%$ \\
\hline Mexico & 10 & 4 & 15 & 12 & 17 & 11 & 18 & 11 & $-5 \%$ \\
\hline Eastern Asia & 171 & 9 & 180 & 51 & 233 & 51 & 233 & 50 & $0 \%$ \\
\hline SE Asia/India & 38 & 73 & 111 & 64 & 97 & 61 & 112 & 75 & $-17 \%$ \\
\hline Australia & 5 & 25 & 30 & 68 & 27 & 68 & 27 & 59 & $9 \%$ \\
\hline Europe & 98 & 3 & 101 & 28 & 142 & 37 & 126 & 31 & $13 \%$ \\
\hline South America & 44 & 71 & 114 & 184 & 102 & 135 & 99 & 125 & $6 \%$ \\
\hline Northern Africa & 47 & 79 & 126 & 121 & 104 & 95 & 101 & 90 & $4 \%$ \\
\hline Southern Africa & 19 & 97 & 116 & 79 & 101 & 69 & 104 & 71 & $-3 \%$ \\
\hline Global & 532 & 396 & 928 & 661 & 982 & 573 & 960 & 553 & $3 \%$ \\
\hline
\end{tabular}

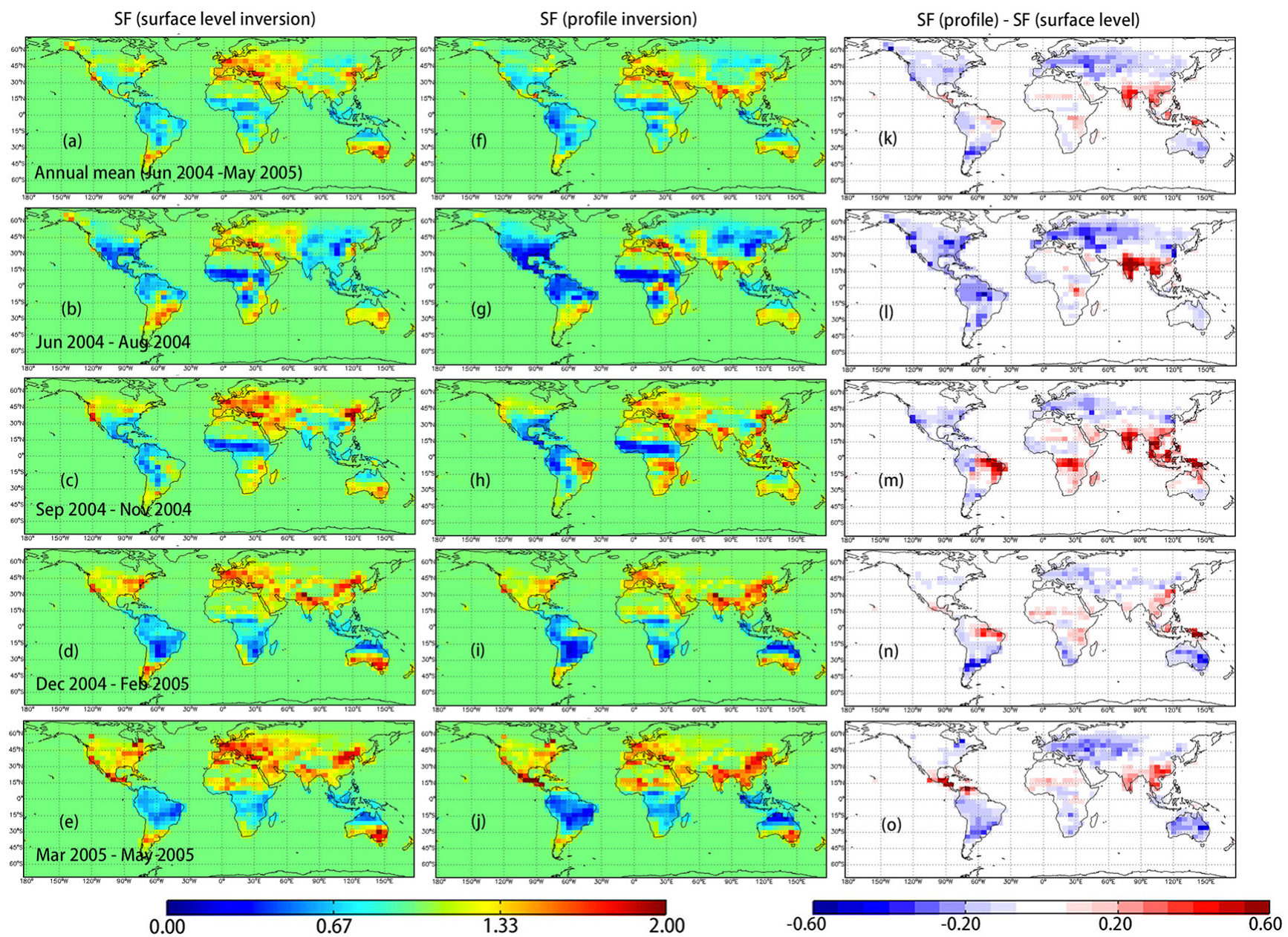

Figure 2. (a-e) Annual/seasonal mean scaling factors, using MOPITT V5J surface level data; (f-j) Annual/seasonal mean scaling factors, using MOPITT V5J tropospheric profile data; $(\mathbf{k}-\mathbf{o})$ Difference between two scaling factors, calculated by middle panel (f, $\mathbf{g}, \mathbf{h}, \mathbf{i}, \mathbf{j})$ minus left panel (a, b, c, d, e). 

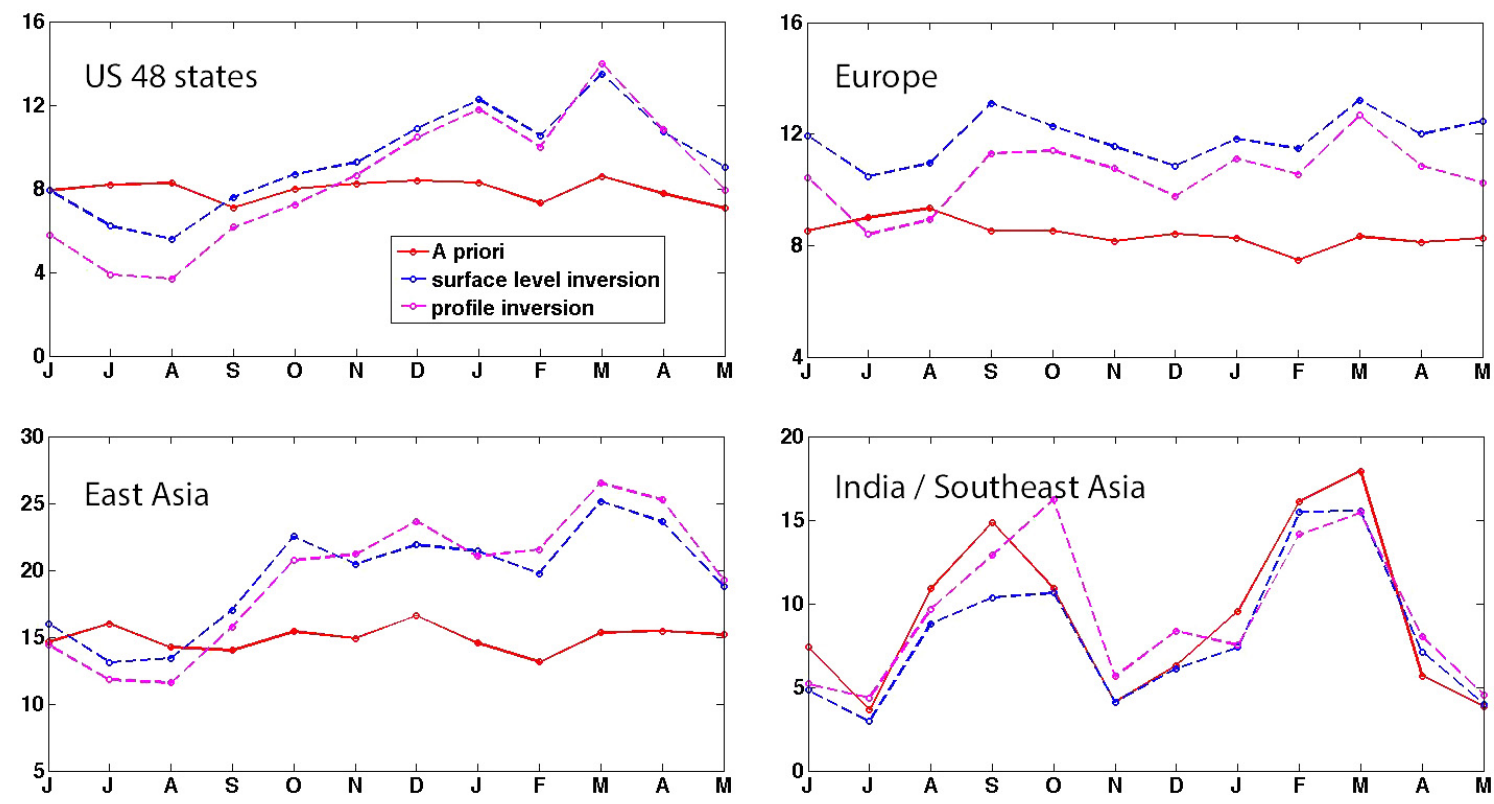

Figure 3. Monthly variation of regional combustion $\mathrm{CO}$ emission estimates.

The seasonal variation of the a posteriori combustion emissions shown in Fig. 3 is consistent with the results of Kopacz et al. (2010). Using data from MOPITT, SCIAMACHY (SCanning Imaging Absorption spectroMeter for Atmospheric CHartographY), and AIRS, Kopacz et al. (2010) showed that the CO emissions from North America, Europe and eastern Asia should be significantly increased in winter. There is also good agreement between the two studies in the aggregated emissions in the extratropical Northern Hemisphere. The total combined a posteriori combustion source from the United States, Alaska, Canada, Europe, and eastern Asia was 515 and $548 \mathrm{Tg}$ from the profile and surface inversions, respectively. The corresponding a posteriori estimate from Kopacz et al. (2010), was 520 Tg.

However, there are large differences in the region source estimates between our analysis and that of Kopacz et al. (2010). For example, our annual combustion emission estimate for the contiguous United States was $100 \mathrm{Tg}$ from the profile inversion, whereas Kopacz et al. (2010) inferred $50 \mathrm{Tg}$. We note that our total a posteriori combustion source estimates for North America of 173 and $156 \mathrm{Tg} \mathrm{CO}$ for the surface layer and profile inversions, respectively, is comparable to the a posteriori estimate of $206 \mathrm{Tg} \mathrm{CO}$ obtained by Fortems-Cheiney et al. (2012) from their inversion analysis of the MOPITT data for 2005. A significant difference between our inversion and that of Kopacz et al. (2010) is that their a priori combustion source for the United States was $40 \mathrm{Tg}$, whereas ours was $112 \mathrm{Tg}$. Their low a priori estimate was based on the results of Hudman et al. (2008), who suggested a $60 \%$ reduction in anthropogenic emissions in the United States as a result of an analysis of aircraft data in July-August 2004. The discrepancies in the regional source estimates between the results here and those of Kopacz et al. (2010) could also be related to differences in the configuration of the inversion analyses, such as the treatment of the initial conditions or vertical transport in the models. Our inversion analyses employed the GEOS-5 meteorological fields, whereas Kopacz et al. (2010) used GEOS-4. A significant factor could be the treatment of the biogenic source of CO. Here the biogenic sources are combined with the combustion sources and optimized at the resolution of the model. In contrast, Kopacz et al. (2010) aggregated the biogenic source with the methane source and optimized the global mean source from methane and VOC oxidation. As shown in Jiang et al. (2011), optimizing the VOC source at a lower resolution than the combustion emissions could result in an over-adjustment of the combustion sources.

In general, we find that the regional source estimates inferred from the surface layer and profile retrievals are consistent, with relative differences of less than $10 \%$, except for source estimates for North America (the United States, Alaska and Canada), Europe, and India/southeastern Asia (see Table 1). The discrepancy between the source estimates for India/southeastern Asia from the two inversions is linked to vertical transport by the Asian monsoon and was discussed by Jiang et al. (2013). In the next section, we present a passive tracer analysis to provide insight into the discrepancies between the source estimates from North America and Europe.

\subsection{Ideal tracer experiments}

It is surprising that Europe and North America (the United States and Canada) are the two regions, after In- 


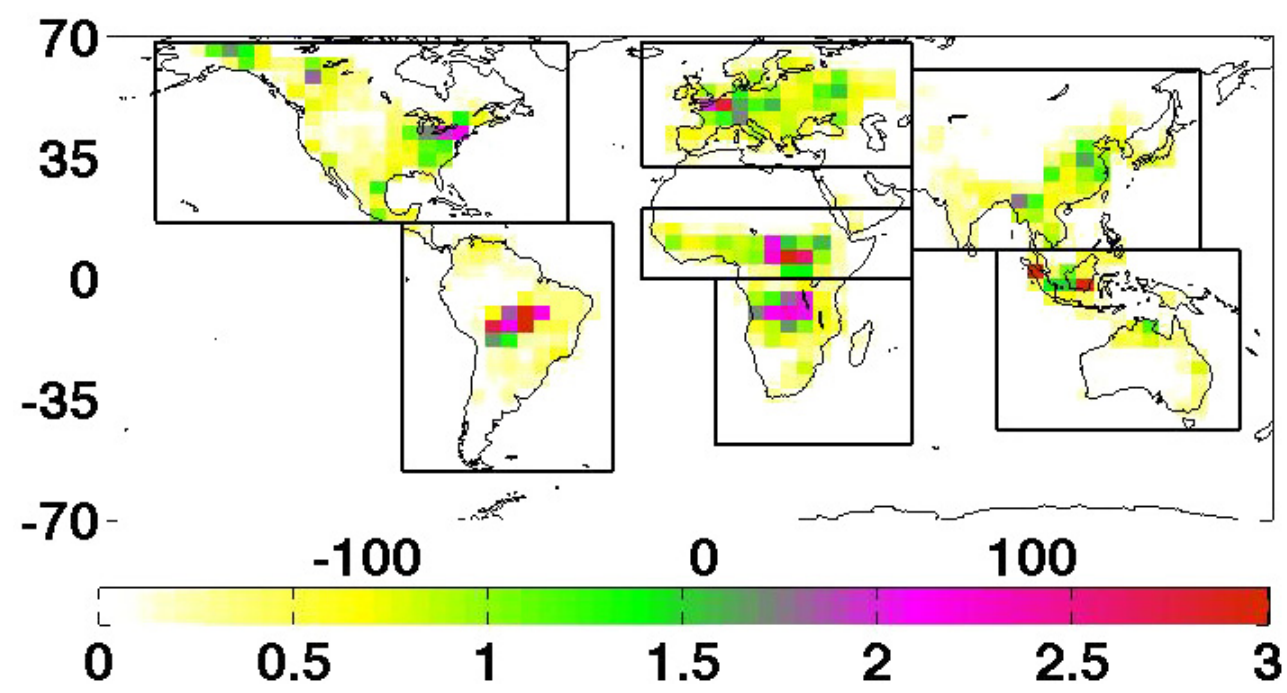

Figure 4. Distribution of emissions used for the idealized 30-day tracer. The unit is $10^{13} \mathrm{molec}^{-2} \mathrm{~s}^{-1}$.

dia/southeastern Asia, with the largest discrepancies between the source estimates inferred from the profile and surface layer inversions. To better understand how the vertical transport of $\mathrm{CO}$ from these regions could impact the inversions, we conducted an analysis using an idealized CO-like tracer. We performed a tagged-CO simulation for the period June 2004-May 2005 in which we imposed a constant source of $\mathrm{CO}$ of $3.33 \mathrm{Tg} \mathrm{CO}$ day $^{-1}$ from each of the continental source regions shown in Fig. 4, with a constant and uniform timescale for loss of 30 days (i.e., the lost rate was given as $[\mathrm{CO}] / 30$ molec cm $^{-3} \mathrm{day}^{-1}$, where $[\mathrm{CO}]$ is the $\mathrm{CO}$ concentration). We ran separate tracers for each of the continental regions, with each tracer emitted only in that region but chemically destroyed everywhere.

The tracers were initialized to a uniformly low abundance of 1 pptv and the model was run for 17 months prior to June 2004 to spin up the tracer distributions. Shown in Fig. 5 are the boundary layer (defined here as the surface- $700 \mathrm{hPa}$ ) and free tropospheric $(700-250 \mathrm{hPa})$ partial columns of the continental tracers for June 2004. In the extratropical Northern Hemisphere, a larger fraction of the Asian surface emissions are exported to the free troposphere, compared to the North American and European emissions. We find that transport of the Asian emissions to the free troposphere is faster even in winter. In the tropics, transport of surface emissions to the free troposphere is slowest for South America (not shown), most likely due to the fact that in boreal summer the ITCZ (Intertropical Convergence Zone) is located in northern South America (in the Northern Hemisphere) and hence transport of south American emissions to the southern subtropics and extratropics is facilitated instead by the influence of mid-latitude cyclones (Staudt et al., 2002). In fall, the ITCZ moves south and convection over South America intensifies (Liu et al., 2010); as a result, we find that, in December, the fraction of South American emissions in the free troposphere is greater, and is comparable to that from northern Africa (not shown).

The monthly mean fraction of the global mass of each continental tracer that is in the boundary layer and the free troposphere is listed in Table 2. North America and Europe have the smallest mass fraction in the free troposphere, 26 and $21 \%$, respectively. This suggests that, relative to the other continental regions, the air in the free troposphere from $\mathrm{Eu}-$ rope and North America is older and more chemically aged. This is consistent with the results of Stohl et al. (2002), who examined the transport of idealized tracers from continental source regions using a Lagrangian particle dispersion model. They found that the European tracer was more confined to the lower troposphere, relative to the North American and Asian tracers. They also noted that "in terms of vertical transport, the North America tracer... behaves intermediately between the Asia and Europe tracers". This suggests that the surface layer and profile inversions are sampling sufficiently different air masses that they obtain different constraints on the North American and European source estimates. The surface layer inversion is sampling air that is less aged and should, therefore, be less susceptible to discrepancies in the $\mathrm{OH}$ abundance.

\subsection{Influence of the $\mathrm{OH}$ distribution}

In this section we compare the impact on the source estimates of the $\mathrm{OH}$ distribution from v8-02-01 of GEOS-Chem with that from our standard inversion (which is based on v5-07-08 of GEOS-Chem). As shown in Fig. 6, v8-02-01 OH is significantly higher than on v5-07-08 in the Northern Hemisphere, while it is much lower over South America and Indonesia.

Using the v8-02-01 OH fields, we repeated the profile and surface inversions for June-August 2004. Shown in Fig. 7 are the scaling factors and their differences, based on the two 

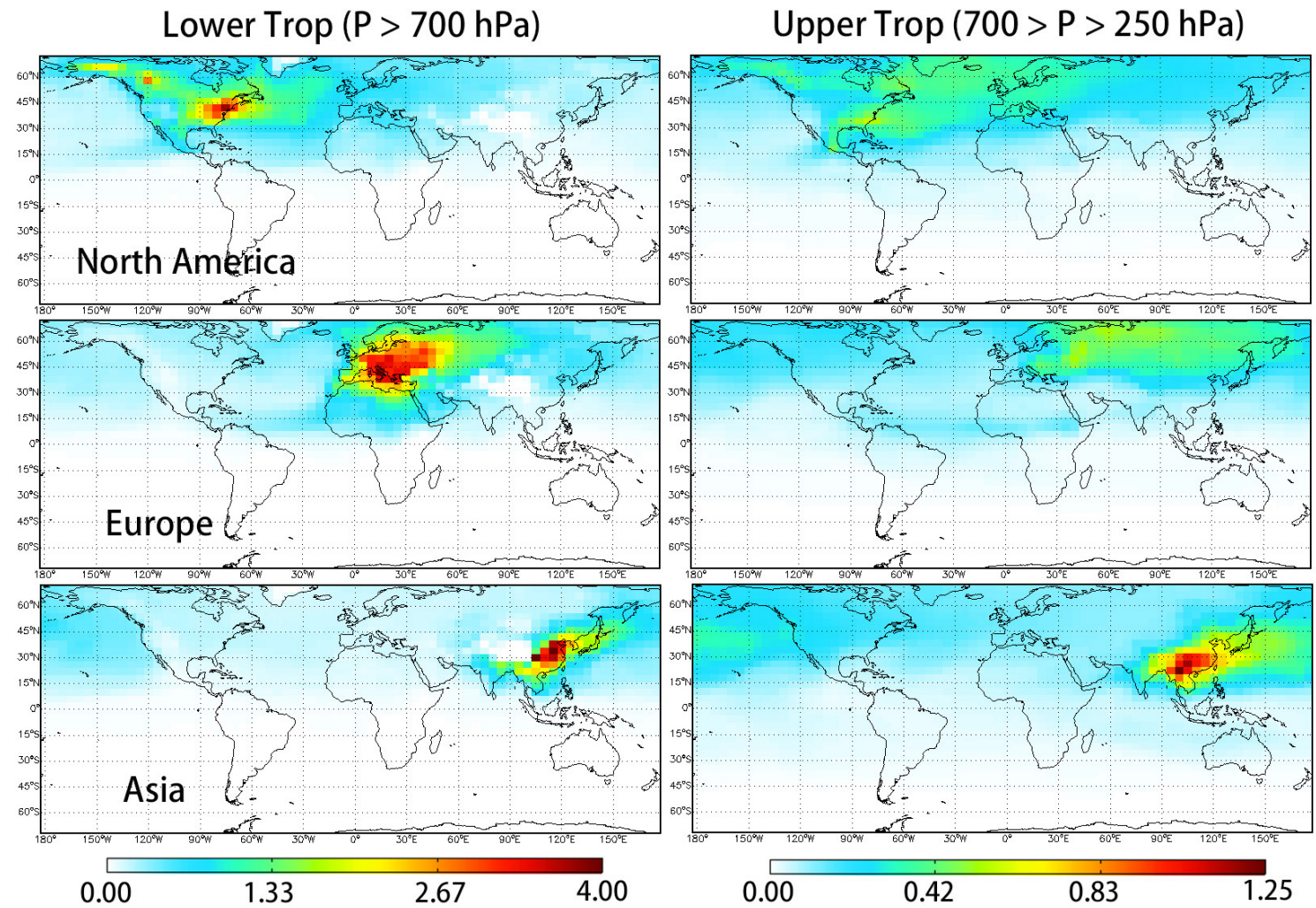

Figure 5. 30-day tracer partial columns in the extratropics for June 2004. The unit is $10^{18} \mathrm{molec} \mathrm{cm}^{-2}$. Note the difference in scales between the lower and upper tropospheric columns.

Table 2. Monthly mean mass of continental CO tracers $(\mathrm{Tg})$ in the boundary layer (lower column) and the free troposphere (upper column). The upper fraction is calculated by Mass_upper / Mass_total. The region definition is shown in Fig. 4.

\begin{tabular}{lrrr}
\hline $\begin{array}{l}\text { Tracer } \\
\text { Tracer }\end{array}$ & $\begin{array}{r}\text { Lower Col } \\
(\mathrm{Tg})\end{array}$ & $\begin{array}{r}\text { Upper Col } \\
(\mathrm{Tg})\end{array}$ & $\begin{array}{r}\text { Upper } \\
\text { fraction }(\%)\end{array}$ \\
\hline North America & 52 & 18 & 26 \\
Europe & 58 & 15 & 21 \\
Asia & 40 & 22 & 35 \\
South America & 40 & 22 & 35 \\
Northern Africa & 36 & 24 & 40 \\
Southern Africa & 34 & 20 & 37 \\
Indonesia & 31 & 24 & 43 \\
\hline
\end{tabular}

versions of the $\mathrm{OH}$ fields. With v8-02-01 OH, the a posteriori emissions in the tropics changed only slightly, while the inferred emission estimates in the extratropics, mainly for North America and Europe, were much greater that those obtained with v5-07-08 $\mathrm{OH}$. The regional source estimates are given in Table 3. For the contiguous United States, with v507-08 $\mathrm{OH}$ we inferred a June-August source of $25.4 \mathrm{Tg} \mathrm{CO}$ using the profile retrievals, whereas with v8-02-01 OH we estimated a source of $49.2 \mathrm{Tg} \mathrm{CO}$. Similarly, for Europe the source estimates inferred from the profile inversion with v5-
07-08 $\mathrm{OH}$ was $47.3 \mathrm{Tg}$, whereas with $\mathrm{v} 8-02-01 \mathrm{OH}$ it with was $68.3 \mathrm{Tg}$.

To help understand the differences in the regional source estimates shown in Table 3, the mean CO lifetime in the tropics and in the northern midlatitudes, for August 2004, are plotted in Fig. 8. Throughout the lower and middle troposphere in the northern midlatitudes, the $\mathrm{CO}$ lifetime is about $30 \%$ shorter with v8-02-01 $\mathrm{OH}$, decreasing to less than 30 days between $900-400 \mathrm{hPa}$.. The shorter lifetime resulted in a reduction of the $\mathrm{CO}$ burden in the midlatitude free troposphere. Consequently, greater extratropical a posteriori source estimates, relative to the v5-07-08 $\mathrm{OH}$ inversions (see Table 3), were required to bring the model into agreement with the MOPITT data. In Jiang et al. (2015), this change in the free tropospheric distribution of $\mathrm{CO}$ is discussed further in the context of a regional inversion analysis for North American source estimates. In the tropics, the CO lifetime increased by about $15 \%$ with v8-02-01 OH. However, as shown in Fig. 6, this reflects reductions in $\mathrm{OH}$ over source regions such as South America and Indonesia, which are partially offset by increases in $\mathrm{OH}$ over northern tropical Africa and the remote tropics. In general, we find that the relative differences between the source estimates from the v8-02-01 and v5-07-08 $\mathrm{OH}$ inversions are smaller for the surface inversion compared to the profile inversion, reflecting the fact 
Table 3. Total CO emission in different regions, in June-August 2004, constrained by MOPITT surface level and tropospheric profile retrievals. The region definition is shown in Fig. 1.

\begin{tabular}{lrrrrr}
\hline & & \multicolumn{2}{c}{ v5-07-08 OH } & \multicolumn{2}{c}{ v8-02-01 OH } \\
\cline { 3 - 6 } Regions & A Priori estimates & Surface level & Profile & Surface level & Profile \\
ing/Jun-Aug) & inversion & inversion & inversion & inversion \\
\hline US 48 states & 50 & 37 & 25 & 55 & 49 \\
Alaska and Canada & 42 & 48 & 41 & 54 & 55 \\
Mexico & 7 & 4 & 3 & 5 & 4 \\
Eastern Asia & 78 & 73 & 66 & 89 & 92 \\
SE Asia/India & 37 & 28 & 35 & 29 & 39 \\
Australia & 14 & 15 & 14 & 16 & 15 \\
Europe & 46 & 57 & 47 & 72 & 68 \\
South America & 75 & 67 & 52 & 68 & 54 \\
Northern Africa & 49 & 34 & 31 & 41 & 40 \\
Southern Africa & 77 & 61 & 60 & 65 & 63 \\
Global & 477 & 425 & 376 & 495 & 481 \\
\hline
\end{tabular}
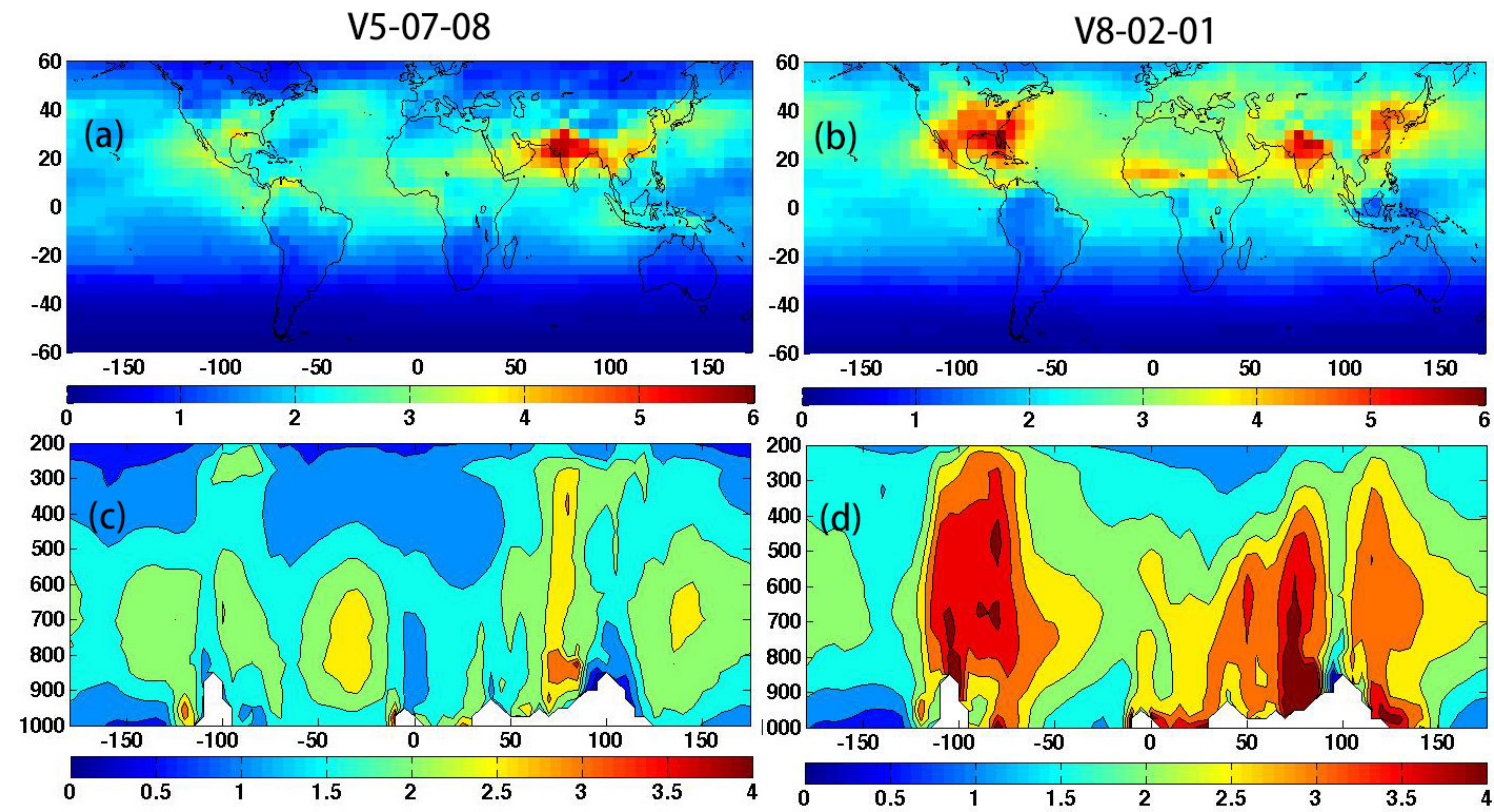

Figure 6. (a, b): Mean tropospheric OH column $\left(10^{12} \mathrm{molec}^{-2}\right)$ in July 2004; (c, d): Meridional mean OH concentration $\left(10^{6}\right.$ molec $\left.\mathrm{cm}^{-3}\right)$ between $20-40^{\circ} \mathrm{N}$ in July 2004.

the surface layer inversion is more strongly influenced by fresh emissions and less by background $\mathrm{CO}$ in the free troposphere.

\section{Summary}

We presented a global inversion analysis to quantify monthly mean CO source estimates during the period of June 2004May 2005 using the version 5 MOPITT retrievals. Building on the work of Jiang et al. (2013), we conducted a comparative analysis of the influence of the MOPITT profile and surface layer retrievals on the inferred $\mathrm{CO}$ source estimates. The inversions suggest a reduction in $\mathrm{CO}$ emission in the tropics, possible due to an overestimate of the biogenic source of $\mathrm{CO}$, and an increase in emissions at middle and high latitudes. In the northern extratropics, we found that the inferred source estimates are typically much greater in winter than in summer, consistent with the seasonality in $\mathrm{CO}$ emissions inferred by Kopacz et al. (2010). With our standard OH distribution, we inferred source estimates of 148,180 , and $284 \mathrm{Tg}$ for the contiguous United States, Europe, and eastern Asia, respectively, using the surface layer retrievals. Using the profile retrievals, the inferred source estimates were lower, 131, 158, and $282 \mathrm{Tg}$, respectively. 

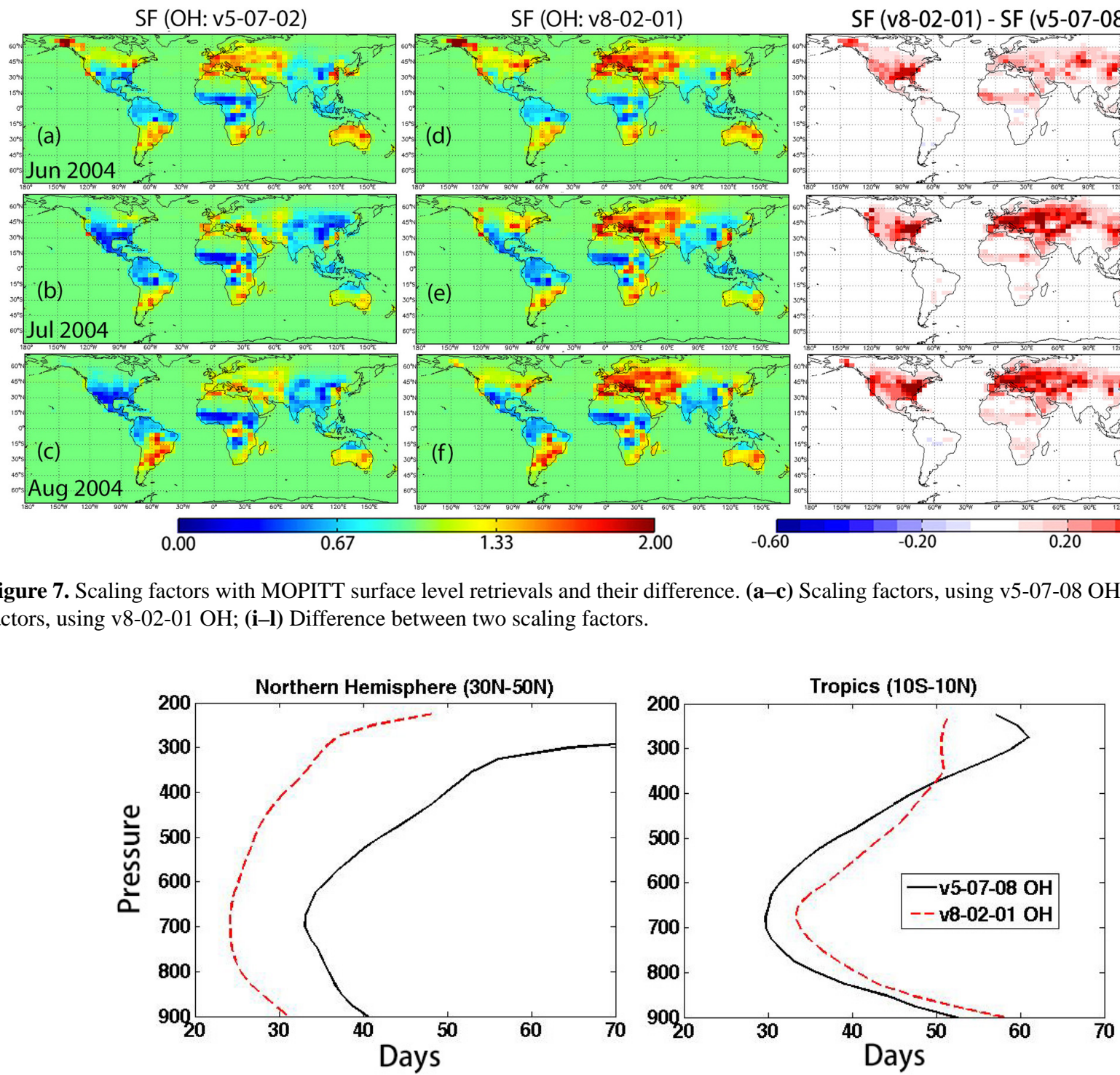

Figure 8. Atmospheric CO lifetime averaged zonally at $30-50^{\circ} \mathrm{N}$ and $10^{\circ} \mathrm{S}-10^{\circ} \mathrm{N}$ for August 2004, estimated using v5-07-08 (black solid line) and v8-02-01 (red dashed line) $\mathrm{OH}$ fields.

In general, we find that the annual mean regional source estimates inferred from the surface layer retrievals and those from the profile retrievals are in agreement with values better than $10 \%$, with the exception of the North American (United States and Canada), European, and Indian/southeastern Asian estimates. The difference in the Indian/southeastern Asian estimates is due to discrepancies in vertical transport associated with the strong convective transport over the southeast Asian region (Jiang et al., 2013). For Europe and North America, we argue that the differences in the source estimates from the profile and surface inversion are due to model discrepancies in the free tropospheric abundance of $\mathrm{CO}$ from these regions. We conducted an ideal tracer experiment and showed that transport of sur- face emissions from Europe and North America to the free troposphere is slower than from other continental regions. Consequently, compared to the inversion using the surface layer retrievals, the profile inversion is sampling older, more chemically aged air from North America and Europe in our simulation, and is, therefore, more susceptible to discrepancies in long-range transport and in the chemical sink of $\mathrm{CO}$. This suggests that diagnostics to assess the age of air from the continental source regions should be useful for interpreting the results from $\mathrm{CO}$ source inversions.

We examined the impact of the $\mathrm{OH}$ distribution on the inferred $\mathrm{CO}$ source estimates, using $\mathrm{OH}$ fields from versions v5-07-08 and v8-02-01 of GEOS-Chem. We found that changing $\mathrm{OH}$ from v5-07-08 (used in our standard in- 
versions) to v8-02-01 produced large differences in the extratropical source estimates. The relative differences in the source estimates from the profile inversion using v5-07-08 and v8-02-01 OH were 64, 33, and $36 \%$ for source estimates from the contiguous United States, eastern Asia, and Europe for June-August 2004, when the CO lifetime is short. In the inversions using the surface layer data we found that the impact of the $\mathrm{OH}$ fields was reduced, but was still large: 40, 20, and $24 \%$, respectively. The smaller impact of the $\mathrm{OH}$ fields in the surface layer inversion is due to the fact that the $\mathrm{OH}$ sink is at a maximum in the middle troposphere, while the surface layer retrievals have maximum sensitivity near the boundary layer.

The results presented here clearly demonstrate the challenge of inverse modeling of $\mathrm{CO}$ emissions. Although the $\mathrm{CO}$ chemistry is relatively simple, the sensitivity to tropospheric $\mathrm{OH}$ is a major issue. Accurate $\mathrm{OH}$ fields are essential for constraining CO reliably. In recent studies, FortemsCheiney et al. (2011) introduced methyl chloroform (MCF) in their $\mathrm{CO}$ inversion to provide a constraint on the $\mathrm{OH}$ abundance. However, MCF is observed at only a few surface sites, hence, although an MCF inversion might give a good global mean $\mathrm{OH}$ constraint, it will not help mitigate discrepancies in the regional distribution of $\mathrm{OH}$. A better method to improve the $\mathrm{OH}$ would be to assimilate tropospheric ozone and it precursors, together with $\mathrm{CO}$, as was done by Miyazaki et al. (2012). They showed that in such a multi-species assimilation, the adjustment in the monthly mean, zonal $\mathrm{OH}$ abundance could be as large as $20 \%$.
Our inversion results also highlight the need to better quantify the isoprene source of CO. Previous studies (e.g., Abbot et al., 2003; Shim et al., 2005; Millet et al., 2008) have used space-based observations of HCHO to inferred isoprene emissions. Since isoprene impacts the tropospheric abundance of $\mathrm{OH}$ and ozone, it may be that the most reliable constraint on the isoprene source will be obtained by jointly assimilating $\mathrm{HCHO}$ data together with observations of $\mathrm{CO}$ and other ozone precursors. In that context, Fortems-Cheiney et al. (2012) conducted a joint inversion analysis using $\mathrm{CO}$, $\mathrm{HCHO}$, methane $\left(\mathrm{CH}_{4}\right)$, and $\mathrm{MCF}$, and found that the biogenic a priori source of $\mathrm{CO}$ was overestimated, whereas the a priori combustion source was underestimated. Our results and those of Fortems-Cheiney et al. (2012) suggest that the way forward will require exploiting a broader range of composition measurements, besides just that of atmospheric $\mathrm{CO}$, to better quantify the regional $\mathrm{CO}$ budget. 


\section{Appendix A: Indirect validation of the MOPITT V5J data}

Although Deeter et al. $(2012,2013)$ showed that the bias in the V5 MOPITT data relative to aircraft observation is small in the lower troposphere, we note that the aircraft data are limited in space and time. Therefore, we conducted an indirect validation of the MOPITT data by assimilating the data to optimize the modeled $\mathrm{CO}$ distribution and compared it with independent data. A better understanding of potential bias in the data is critical for properly quantifying the source estimates. Comparison of the $\mathrm{CO}$ distribution obtained with the a posteriori source estimates can reveal potential bias in the inversion, but in that approach it is difficult to determine whether the bias is in the data or the model. By constraining the modeled $\mathrm{CO}$ to match the observations, we can more easily identify potential biases in the data. For example, recent inversion studies (Arellano et al., 2006; Jones et al., 2009; Hooghiemstra et al., 2012) have shown that the a posteriori CO emissions, inferred from MOPITT data, resulted in an overestimate of $\mathrm{CO}$ abundances relative to surface in situ measurements. Hooghiemstra et al. (2012) suggested that the overestimate of surface $\mathrm{CO}$ was due to a bias in the V4 MOPITT data that they employed. However, Arellano et al. (2006) and Jones et al. (2009) used the V3 MOPITT product in their inversion analyses. Jiang et al. (2013) suggested that the bias seen by Hooghiemstra et al. (2012) could be due to discrepancies in vertical transport. We also note that MOPITT validation comparisons (Deeter et al., 2010; 2013) over land rely on NOAA aircraft in situ CO profiles that are concentrated in North America with only 2 out of 15 locations at latitudes higher than $50^{\circ} \mathrm{N}$.

To assess potential bias in the MOPITT data set, we assimilated the MOPITT V5J CO profile data into the GEOSChem model using the sequential sub-optimal Kalman filter and compared the resulting CO field with GMD in situ surface $\mathrm{CO}$ observations. Figure A1 shows the comparison of the assimilated $\mathrm{CO}$ with monthly mean $\mathrm{CO}$ concentrations at selected GMD sites. We first compared the free model simulation (the standard GEOS-Chem simulation without Kalman filter assimilation) with GMD data. The initial condition for the free model run is the model original initial condition on 1 June 2004, without optimization. In the Northern Hemisphere, the CO concentration of the free run model is higher than that of GMD in summer and fall, and significantly lower than that of GMD in winter and spring. In the Southern Hemisphere, the free run model generally overestimates the observed $\mathrm{CO}$, which is consistent with previous studies (Shindell et al., 2006; Kopacz et al., 2010). In our assimilation, we first assimilated the MOPITT profile data between $60^{\circ} \mathrm{S}$ to $60^{\circ} \mathrm{N}$. The result shows that the assimilated MOPITT data (dark blue dotted line) are highly consistent with the GMD data between 0 to $30^{\circ} \mathrm{N}$. However, the analysis has a positive bias in the mid-latitudes of the Southern Hemisphere and in the high latitudes of the Northern Hemi- sphere, such as at Cold Bay (CBA), Alaska, and Mace Head (MHD), Ireland. In the Southern Hemisphere, at Crozet Island (CGO), the a priori is biased high and the assimilation exacerbated the bias. Although Hooghiemstra et al. (2012) used V4 MOPITT data, our results suggests that the V5J data may also be biased high in the Southern Hemisphere. To reduce the potential impact of this high latitude bias in both hemispheres, we omitted MOPITT data in the assimilation that are polarward of $40^{\circ}$ over oceans and $52^{\circ}$ over land. As shown in Fig. A1, this improved the agreement between the assimilated CO and the GMD data, but it did not completely remove the positive high-latitude bias at MHD and CGO. The results in Fig. A1 show the value in the optimized initial conditions prior to the source estimation. The initial condition biases are much smaller than using original initial conditions from the free running model, particularly in winter and spring.

\section{Appendix B: Optimization of the cost function}

For the results presented here, the state vector in Eq. (2) is not the $\mathrm{CO}$ emissions, but is a set scaling factors $\sigma$ such that $\hat{\boldsymbol{x}}=\sigma \boldsymbol{x}_{\mathrm{a}}$. Consequently, the optimization is conducted by minimizing the gradient of the cost function with respect to the scaling factors, with errors in the emission inventories assumed on a relative basis rather than on an absolute basis. In this approach, the gradient of the cost function as described in Eq. (2) is usually scaled as follows:

$\frac{\partial J}{\partial\left(\boldsymbol{x} / \boldsymbol{x}_{\mathrm{a}}\right)}=\frac{\partial J}{\partial \boldsymbol{x}} \cdot \boldsymbol{x}_{\mathrm{a}}$.

This method is referred to as the linear scaling factor optimization. It assumes that the uncertainty in the emissions is normally distributed about a scaling factor 1 . Henze et al. (2009) indicated that the normal distribution of about 1 is nonphysical because it allows for negative emissions. An alternative method is the logarithm (LOG) scaling factor optimization (Henze et al., 2009):

$\frac{\partial J}{\partial \ln \left(\boldsymbol{x} / \boldsymbol{x}_{\mathrm{a}}\right)}=\frac{\partial J}{\partial \boldsymbol{x}} \cdot \boldsymbol{x}_{\mathrm{a}} \cdot \frac{\boldsymbol{x}}{\boldsymbol{x}_{\mathrm{a}}}$.

It represents a log-normal distribution of scaling factors about zero. One advantage of LOG scaling factor optimization is that it can prevent negative scaling factors (Henze et al., 2009). However, it does not reduce negative gradients effectively because the increase in the factor $x / x_{\mathrm{a}}$ will partially offset the decrease of $\partial J / \partial x$. For example, assuming a negative gradient due to the model being lower than measurements (for example, $\partial J / \partial x=-100$ ), the inversion will increase emission (for example, $x / x_{\mathrm{a}}=1.5$ ) to reduce the negative gradient (for example, to $\partial J / \partial x=-66.7$ ). Using linear scaling factor optimization, we will see $33 \%$ improvement (reduction) of the gradient. However, using LOG scaling factor optimization, there is no improvement of the gradient because $\partial J / \partial x \times x / x_{\mathrm{a}}=-66.7 \times 1.5=-100$. 

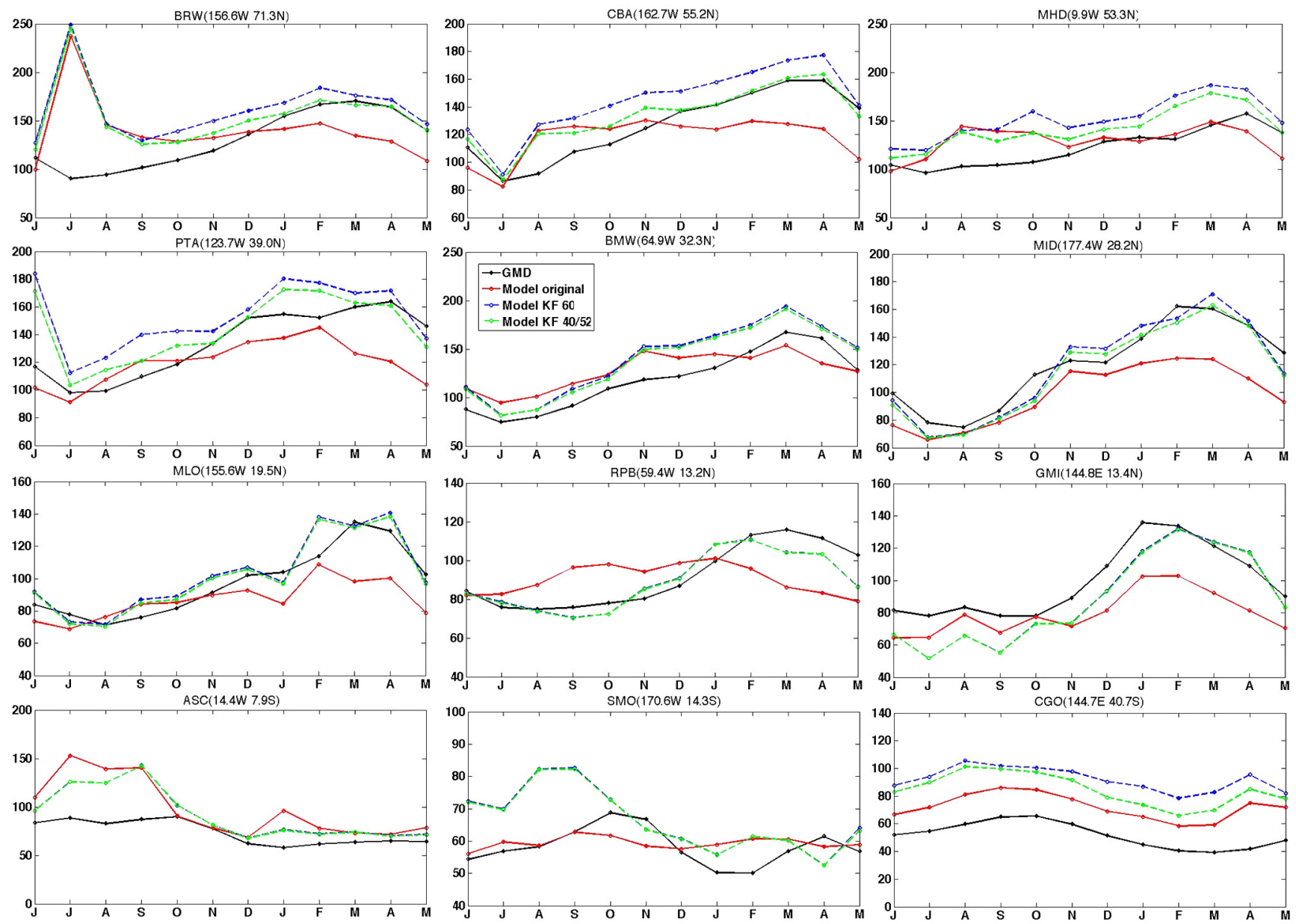

Figure A1. Annual variation of monthly mean CO concentration at selected GMD sites and surface level CO in GEOS-Chem, sampled at the GMD sites. The black solid line shows the GMD monthly mean CO. The red solid line shows the free model simulation with original initial condition. The blue dashed line is the assimilation result using MOPITT from $60^{\circ} \mathrm{S}$ to $60^{\circ} \mathrm{N}$. The green dashed line is the assimilation result from excluding the high latitude data.

Figure B1 shows the results of the linear scaling optimization and the LOG optimization in a simulation experiment for April 2006. In the experiment, we created pseudo observations by archiving the model output with the $\mathrm{CO}$ emissions unchanged (the default $\mathrm{CO}$ emission inventory). In the inversion analysis of the pseudo data, we then reduce the $\mathrm{CO}$ emission by $50 \%$ so that the objective of the experiment is to produce scaling factors that can return the source estimate to the default emissions (i.e., scaling factors of 1.0). According to Eqs. (B1-B3), grids with strong $\mathrm{CO}$ emissions, such as those in eastern Asia, India, equatorial Africa and South America, will have a large initial gradient. Because the cost function is minimized in regions where the gradients are the largest, these strong emission regions will be optimized preferentially. After 30 iterations, the a posteriori estimate with linear method (Fig. B1a) converges to the true state in all major emission regions. The results with LOG method are clearly worse (Fig. B1b).
To better reduce the negative gradient, and avoid negative scaling factors, we developed the following modification to the LOG method:

$$
\begin{aligned}
& \frac{\partial J}{\partial \ln \left(\boldsymbol{x} / \boldsymbol{x}_{\mathrm{a}}\right)}=\frac{\partial J}{\partial \boldsymbol{x}} \cdot \boldsymbol{x}_{\mathrm{a}} \cdot \frac{\boldsymbol{x}}{\boldsymbol{x}_{\mathrm{a}}} \text { when }: \frac{\boldsymbol{x}}{\boldsymbol{x}_{\mathrm{a}}} \leq 1 \\
& \frac{\partial J}{\partial \frac{1}{2}\left[\left(\boldsymbol{x} / \boldsymbol{x}_{\mathrm{a}}\right)^{2}-1\right]}=\frac{\partial J}{\partial \boldsymbol{x}} \cdot \boldsymbol{x}_{\mathrm{a}} / \frac{\boldsymbol{x}}{\boldsymbol{x}_{\mathrm{a}}} \text { when }: \frac{\boldsymbol{x}}{\boldsymbol{x}_{\mathrm{a}}}>1 .
\end{aligned}
$$

This new method is referred to as "LOGX2". It can minimize the positive and negative gradients with comparable efficiency. As shown in Fig. B1c, the optimization effect of the LOGX2 method is slightly better than that of the linear method. However, it should be noted that although the LOGX2 approach improves the optimization efficiency and minimizes the potential systematic errors, it impacts the statistics of the solution. With the linear or LOG approaches the errors are Gaussian or log-normal, respectively, but with the LOGX2 scheme they are neither. 

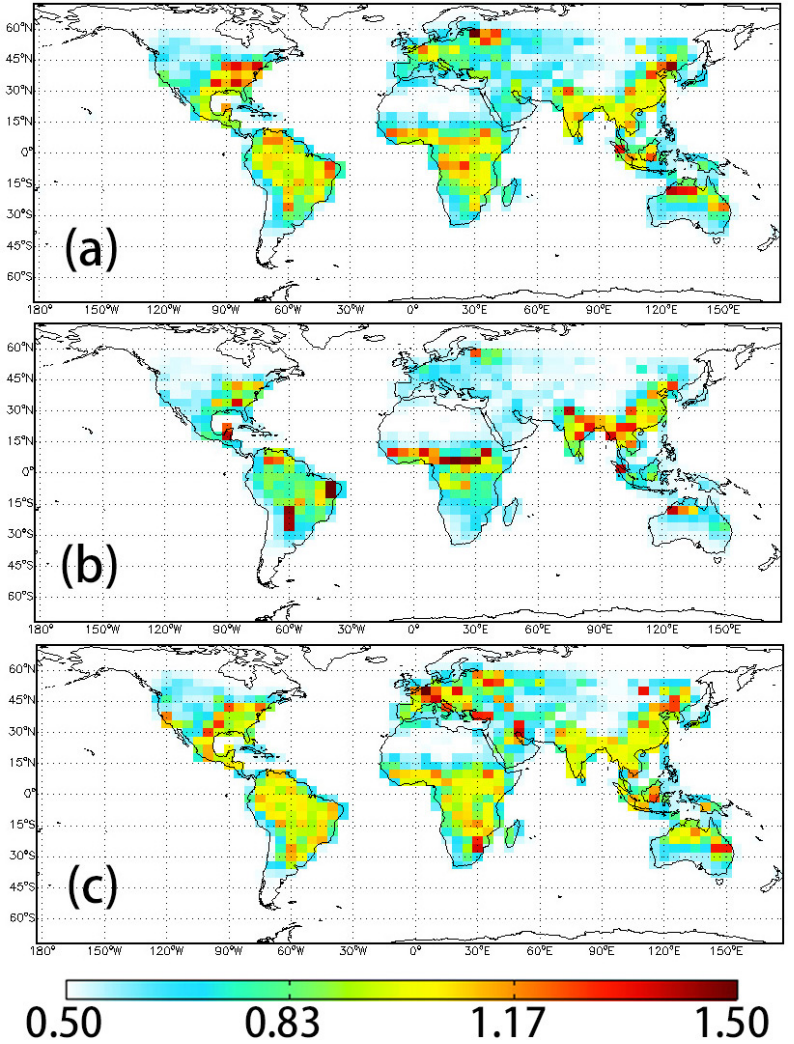

Figure B1. OSSE (Observing System Simulation Experiments) scaling factors for April 2006. The scaling factors represent the ratio of the estimated to true emissions. The ratio for the first guess is 0.5 . The actual value is 1.0. Shown are the scaling factors obtained with (a) the linear scaling factor optimization, (b) the LOG scaling factor optimization, (c) the LOGX2 scaling factor optimization.

Acknowledgements. This work was supported by funding from the Natural Science and Engineering Research Council of Canada, the Canadian Space Agency, and NASA grant NNX10AT42G. We thank NOAA ESRL for providing their CO flask data. We also thank the two anonymous reviewers for their thoughtful and detailed comments on the manuscript.

Edited by: M. Kopacz

\section{References}

Abbot, D. S., Palmer, P. I., Martin, R. V., Chance, K. V., Jacob, D. J., and Guenther, A.: Seasonal and interannual variability of North American isoprene emissions as determined by formaldehyde column measurements from space, Geophys. Res. Lett., 30, 1886, doi:10.1029/2003GL017336, 2003.

Arellano Jr., A. F. and Hess, P. G.: Sensitivity of top-down estimates of CO sources to GCTM transport, Geophys. Res. Lett., 31, L21807, doi:10.1029/2006GL027371, 2006.

Arellano Jr., A. F., Kasibhatla, P. S., Giglio, L., van der Werf, G. R., Randerson, J. T., and Collatz, G. J.: Time dependent inversion estimates of global biomass-burning $\mathrm{CO}$ emissions using Measure- ment of Pollution in the Troposphere (MOPITT) measurements, J. Geophys. Res., 111, D09303, doi:10.1029/2005JD006613, 2006.

Barkley, M. P., Palmer, P. I., Kuhn, U., Kesselmeier, J., Chance, K., Kurosu, T. P., Martin, R. V., Helmig, D., and Guenther, A.: Net ecosystem fluxes of isoprene over tropical South America inferred from Global Ozone Monitoring Experiment (GOME) observations of HCHO columns, J. Geophys. Res., 113, D20304, doi:10.1029/2008JD009863, 2008.

Deeter, M. N., Emmons, L. K., Francis, G. L., Edwards, D. P., Gille, J. C., Warner, J. X., Khattatov, B., Ziskin, D., Lamarque, J.-F., Ho, S.-P., Yudin, V., Attie, J.-L., Packman, D., Chen, J., Mao, D., and Drummond, J. R.: Operational carbon monoxide retrieval algorithm and selected results for the MOPITT instrument, J. Geophys. Res., 108, 4399, doi:10.1029/2002JD003186, 2003.

Deeter, M. N., Edwards, D. P., Gille, J. C., Emmons, L. K., Francis, G., Ho, S.-P., Mao, D., Masters, D., Worden, H., Drummond, J. R., and Novelli, P. C.: The MOPITT version 4 CO product: Algorithm enhancements, validation, and long-term stability, J. Geophys. Res., 115, D07306, doi:10.1029/2009JD013005, 2010.

Deeter, M. N., Worden, H. M., Gille, J. C., Edwards, D. P., Mao, D., and Drummond, J. R.: MOPITT multispectral CO retrievals: Origins and effects of geophysical radiance errors, J. Geophys. Res., 116, D15303, doi:10.1029/2011JD015703, 2011.

Deeter, M. N., Worden, H. M., Edwards, D. P., Gille, J. C., and Andrews, A. E.: Evaluation of MOPITT retrievals of lowertropospheric carbon monoxide over the United States, J. Geophys. Res., 117, D13306, doi:10.1029/2012JD017553, 2012.

Deeter, M. N., Martínez-Alonso, S., Edwards, D. P., Emmons, L. K., Gille, J. C., Worden, H. M., Pittman, J. V., Daube, B. C., and Wofsy, S. C.: Validation of MOPITT Version 5 thermalinfrared, near-infrared, and multispectral carbon monoxide profile retrievals for 2000-2011, J. Geophys. Res. Atmos., 118, 6710-6725, doi:10.1002/jgrd.50272, 2013.

Evans, M. J. and Jacob, D. J.: Impact of new laboratory studies of $\mathrm{N}_{2} \mathrm{O}_{5}$ hydrolysis on global model budgets of tropospheric nitrogen oxides, ozone, and OH, Geophys. Res. Lett., 32, L09813, doi:10.1029/2005GL022469, 2005.

Fortems-Cheiney, A., Chevallier, F., Pison, I., Bousquet, P., Szopa, S., Deeter, M. N., and Clerbaux, C.: Ten years of $\mathrm{CO}$ emissions as seen from Measurements of Pollution in the Troposphere (MOPITT), J. Geophys. Res., 116, D05304, doi:10.1029/2010JD014416, 2011.

Fortems-Cheiney, A., Chevallier, F., Pison, I., Bousquet, P., Saunois, M., Szopa, S., Cressot, C., Kurosu, T. P., Chance, K., and Fried, A.: The formaldehyde budget as seen by a global-scale multiconstraint and multi-species inversion system, Atmos. Chem. Phys., 12, 6699-6721, doi:10.5194/acp-12-6699-2012, 2012.

George, M., Clerbaux, C., Hurtmans, D., Turquety, S., Coheur, P.F., Pommier, M., Hadji-Lazaro, J., Edwards, D. P., Worden, H., Luo, M., Rinsland, C., and McMillan, W.: Carbon monoxide distributions from the IASI/METOP mission: evaluation with other space-borne remote sensors, Atmos. Chem. Phys., 9, 8317-8330, doi:10.5194/acp-9-8317-2009, 2009.

Gonzi, S., Feng, L., and Palmer, P. I.: Seasonal cycle of emissions of CO inferred from MOPITT profiles of CO: Sensitivity to pyroconvection and profile retrieval assumptions, Geophys. Res. Lett., 38, L08813, doi:10.1029/2011GL046789, 2011. 
Guenther, A., Karl, T., Harley, P., Wiedinmyer, C., Palmer, P. I., and Geron, C.: Estimates of global terrestrial isoprene emissions using MEGAN (Model of Emissions of Gases and Aerosols from Nature), Atmos. Chem. Phys., 6, 3181-3210, doi:10.5194/acp-63181-2006, 2006.

Heald, C. L., Jacob, D. J., Jones, D. B. A., Palmer, P. I., Logan ,J. A., Streets, D. G., Sachse, G. W., Gille, J. C., Hoffman, R. N., and Nehrkorn, T.: Comparative inverse analysis of satellite (MOPITT) and aircraft (TRACE-P) observations to estimate Asian sources of carbon monoxide, J. Geophys. Res. 109, D23306, doi:10.1029/2004JD005185, 2004.

Henze, D. K., Hakami, A., and Seinfeld, J. H.: Development of the adjoint of GEOS-Chem, Atmos. Chem. Phys., 7, 2413-2433, doi:10.5194/acp-7-2413-2007, 2007.

Henze, D. K., Seinfeld, J. H., and Shindell, D. T.: Inverse modeling and mapping US air quality influences of inorganic PM2.5 precursor emissions using the adjoint of GEOS-Chem, Atmos. Chem. Phys., 9, 5877-5903, doi:10.5194/acp-9-5877-2009, 2009.

Hooghiemstra, Krol, M. C., Bergamaschi, P., de Laat, A. T. J., van der Werf, G. R., Novelli, P. C., Deeter, M. N., Aben, I., and Röckmann, T.: Comparing optimized $\mathrm{CO}$ emission estimates using MOPITT or NOAA surface network observations, J. Geophys. Res. 117, D06309, doi:10.1029/2011JD017043, 2012.

Hudman, R. C., Murray, L. T., Jacob, D. J., Millet, D. B., Turquety, S., Wu, S., Blake, D. R., Goldstein, A. H., Holloway, J., and Sachse, G. W.: Biogenic versus anthropogenic sources of CO in the United States, Geophys. Res. Lett., 35, L04801, doi:10.1029/2007GL032393, 2008.

Jiang, Z., D. Jones, B. A., Kopacz, M., Liu, J., Henze, D. K., and Heald, C.: Quantifying the impact of model errors on top-down estimates of carbon monoxide emissions using satellite observations, J. Geophys. Res., 116, D15306, doi:10.1029/2010JD015282, 2011.

Jiang, Z., Jones, D. B. A., Worden, H. M., Deeter, M. N., Henze, D. K., Worden, J., Bowman, K. W., Brenninkmeijer, C. A. M., and Schuck, T. J.: Impact of model errors in convective transport on $\mathrm{CO}$ source estimates inferred from MOPITT CO retrievals, J. Geophys. Res. Atmos., 118, 2073-2083, doi:10.1002/jgrd.50216, 2013.

Jiang, Z., Jones, D. B. A., Worden, J. R., Worden, H. M., Henze, D. K., and Wang, Y. X.: Regional data assimilation of multi-spectral MOPITT observations of CO over North America, submitted, Atmos. Chem. Phys. Discuss., 2015.

Jones, D. B. A., Bowman, K. W., Logan, J. A., Heald, C. L., Liu, J., Luo, M., Worden, J., and Drummond, J.: The zonal structure of tropical $\mathrm{O} 3$ and $\mathrm{CO}$ as observed by the Tropospheric Emission Spectrometer in November 2004 - Part 1: Inverse modeling of CO emissions, Atmos. Chem. Phys., 9, 3547-3562, doi:10.5194/acp-9-3547-2009, 2009.

Keller, M., Jones, D. B. A., Jiang, Z., and Henze, D. K.: Quantifying Model Biases in CO Emission Estimation Using Weak Constraint 4-D-var, in preparation, 2015.

Kopacz, M., Jacob, D. J., Henze, D. K., Heald, C. L., Streets, D. G., and Zhang, Q.: Comparison of adjoint and analytical Bayesian inversion methods for constraining Asian sources of carbon monoxide using satellite (MOPITT) measurements of CO columns, J. Geophys. Res., 114, D04305, doi:10.1029/2007JD009264, 2009.
Kopacz, M., Jacob, D. J., Fisher, J. A., Logan, J. A., Zhang, L., Megretskaia, I. A., Yantosca, R. M., Singh, K., Henze, D. K., Burrows, J. P., Buchwitz, M., Khlystova, I., McMillan, W. W., Gille, J. C., Edwards, D. P., Eldering, A., Thouret, V., and Nedelec, P.: Global estimates of $\mathrm{CO}$ sources with high resolution by adjoint inversion of multiple satellite datasets (MOPITT, AIRS, SCIAMACHY, TES), Atmos. Chem. Phys., 10, 855-876, doi:10.5194/acp-10-855-2010, 2010.

Kuhns, H., Green, M., and Etyemezian, V.: Big Bend Regional Aerosol and Visibility Observational (BRAVO) Study Emissions Inventory, Report prepared for BRAVO Steering Committee, Desert Research Institute, Las Vegas, Nevada, 2003.

Liu, J.-H., Logan, J. A., Jones, D. B. A., Livesey, N. J., Megretskaia, I., Carouge, C., and Nedelec, P.: Analysis of CO in the tropical troposphere using Aura satellite data and the GEOS-Chem model: insights into transport characteristics of the GEOS meteorological products, Atmos. Chem. Phys., 10, 12207-12232, doi:10.5194/acp-10-12207-2010, 2010.

Luo, M., Rinsland, C. P., Rodgers, C. D., Logan, J. A., Worden, H., Kulawik, S., Eldering, A., Goldman, A., Shephard, M. W., Gunson, M., and Lampel, M.: Comparison of carbon monoxide measurements by TES and MOPITT: The influence of a priori data and instrument characteristics on nadir atmospheric species retrievals, J. Geophys. Res., 112, D09303, doi:10.1029/2006JD007663, 2007.

Marais, E. A., Jacob, D. J., Guenther, A., Chance, K., Kurosu, T. P., Murphy, J. G., Reeves, C. E., and Pye, H. O. T.: Improved model of isoprene emissions in Africa using Ozone Monitoring Instrument (OMI) satellite observations of formaldehyde: implications for oxidants and particulate matter, Atmos. Chem. Phys., 14, 7693-7703, doi:10.5194/acp-14-7693-2014, 2014.

Millet, D. B., Jacob, D. J., Boersma, K. F., Fu, T.-M., Kurosu, T. P., Chance, K., Heald, C. L., and Guenther, A.: Spatial distribution of isoprene emissions from North America derived from formaldehyde column measurements by the OMI satellite sensor, J. Geophys. Res., 113, D02307, doi:10.1029/2007JD008950, 2008.

Miyazaki, K., Eskes, H. J., Sudo, K., Takigawa, M., van Weele, M., and Boersma, K. F.: Simultaneous assimilation of satellite $\mathrm{NO}_{2}$, $\mathrm{O}_{3}, \mathrm{CO}$, and $\mathrm{HNO}_{3}$ data for the analysis of tropospheric chemical composition and emissions, Atmos. Chem. Phys., 12, 95459579, doi:10.5194/acp-12-9545-2012, 2012.

Olivier, J. G. J. and Berdowski, J. J. M.: Global emissions sources and sinks, in: The Climate System, edited by: Berdowski, J., Guicherit, R., and Heij, B. J., 33-78, A. A. Balkema Publishers/Swets \& Zeitlinger Publishers, Lisse, the Netherlands, 2001.

Ott, L. E., Bacmeister, J., Pawson, S., Pickering, K., Stenchikov, G., Suarez, M., Huntrieser, H., Loewenstein, M., Lopez, J., and Xueref-Remy, I.: Analysis of Convective Transport and Parameter Sensitivity in a Single Column Version of the Goddard Earth Observation System, Version 5, General Circulation Model, J. Atmos. Sci., 66, 627-646, doi:10.1175/2008JAS2694.1, 2009.

Palmer, P. I., Jacob, D. J., Jones, D. B. A., Heald, C. L., Yantosca, R. M., Logan, J. A. Sachse, G. W., and Streets, D. G.: Inverting for emissions of carbon monoxide from Asia using aircraft observations over the western Pacific, J. Geophys. Res., 108, 8828, doi:10.1029/2003JD003397, 2003.

Palmer, P. I., Suntharalingam, P., Jones, D. B. A., Jacob, D. J., Streets, D. G., Fu, Q., Vay, S. A., and Sachse, G. 
W.: Using $\mathrm{CO}_{2}$ :CO correlations to improve inverse analyses of carbon fluxes, J. Geophys. Res., 111, D12318, doi:10.1029/2005JD006697, 2006.

Parrington, M., Jones, D. B. A., Bowman, K. W., Horowitz, L. W., Thompson, A. M., Tarasick, D. W., and Witte, J. C.: Estimating the summertime tropospheric ozone distribution over North America through assimilation of observations from the Tropospheric Emission Spectrometer, J. Geophys. Res., 113, D18307, doi:10.1029/2007JD009341, 2008.

Parrington, M., Palmer, P. I., Henze, D. K., Tarasick, D. W., Hyer, E. J., Owen, R. C., Helmig, D., Clerbaux, C., Bowman, K. W., Deeter, M. N., Barratt, E. M., Coheur, P.-F., Hurtmans, D., Jiang, Z., George, M., and Worden, J. R.: The influence of boreal biomass burning emissions on the distribution of tropospheric ozone over North America and the North Atlantic during 2010, Atmos. Chem. Phys., 12, 2077-2098, doi:10.5194/acp-12-20772012, 2012.

Pétron, G., Granier, C., Khattatov, B., Yudin, V., Lamarque, J.-F., Emmons, L., Gille, J., and Edwards, D. P.: Monthly CO surface sources inventory based on the 2000-2001 MOPITT satellite data, Geophys. Res. Lett., 31, L21107, doi:10.1029/2004GL020560, 2004.

Shim, C., Wang, Y.-H., Choi, Y., Palmer, P. I., Abbot, D. S., and Chance, K: Constraining global isoprene emissions with Global Ozone Monitoring Experiment (GOME) formaldehyde column measurements, J. Geophys. Res., 110, D24301, doi:10.1029/2004JD005629, 2005.

Shindell, D. T., Faluvegi, G., Stevenson, D. S., Krol, M. C., Emmons, L. K., Lamarque, J.-F., Petron, G., Dentener, F. J., Ellingsen, K., Schultz, M. G., Wild, O, Amann, M., Atherton, C. S., Bergmann, D. J., Bey, I., Butler, T., Cofala, J., Collins, W. J., Derwent, R. G., Doherty, R. M., Drevet, J., Eskes, H. J., Fiore, A. M., Gauss, M., Hauglustaine, D. A., Horowitz, L. W., Isaksen, S. A., Lawrence, M. G., Montanaro, V., Muller, J.-F., Pitari, G., Parther, M. J., Pyle, J. A., Rast, S., Rodriguez, J. M., Sanderson, M. G., Savage, N. H., Strahan, S. E., Sudo, K., Szopa, S., Unger, N., van Noije, T. P. C., and Zeng, G.: Multimodel simulations of carbon monoxide: Comparison with observations and projected near-future changes, J. Geophys. Res., 111, D19306, doi:10.1029/2006JD007100, 2006.

Singh, K., Jardak, M., Sandu, A., Bowman, K., Lee, M., and Jones, D.: Construction of non-diagonal background error covariance matrices for global chemical data assimilation, Geosci. Model Dev., 4, 299-316, doi:10.5194/gmd-4-299-2011, 2011.

Staudt, A. C., Jacob, D. J., Logan, J. A., Bachiochi, D., Krishnamurti, T. N., and Poisson, N.: Global chemical model analysis of biomass burning and lightning influences over the South Pacific in austral spring, J. Geophys. Res., 107, ACH 11-1-ACH 11-17, doi:10.1029/2000JD000296, 2002.
Stein, O., Schultz, M. G., Bouarar, I., Clark, H., Huijnen, V., Gaudel, A., George, M., and Clerbaux, C.: On the wintertime low bias of Northern Hemisphere carbon monoxide found in global model simulations, Atmos. Chem. Phys., 14, 9295-9316, doi:10.5194/acp-14-9295-2014, 2014.

Stohl, A., Eckhardt, S., Forster, C., James, P., and Spichtinger, N.: On the pathways and timescales of intercontinental air pollution transport, J. Geophys. Res., 107, 4684, doi:10.1029/2001JD001396, 2002.

Vestreng, V. and Klein, H.: Emission data reported to UNECE/EMEP. Quality assurance and trend analysis and Presentation of WebDab, Norwegian Meteorological Institute, Oslo, Norway, MSC-W Status Report, 2002.

van der Werf, G. R., Randerson, J. T., Giglio, L., Collatz, G. J., Mu, M., Kasibhatla, P. S., Morton, D. C., DeFries, R. S., Jin, Y., and van Leeuwen, T. T.: Global fire emissions and the contribution of deforestation, savanna, forest, agricultural, and peat fires (19972009), Atmos. Chem. Phys., 10, 11707-11735, doi:10.5194/acp10-11707-2010, 2010.

Wang, H., Jacob, D. J., Kopacz, M., Jones, D. B. A., Suntharalingam, P., Fisher, J. A., Nassar, R., Pawson, S., and Nielsen, J. E.: Error correlation between $\mathrm{CO}_{2}$ and $\mathrm{CO}$ as constraint for $\mathrm{CO}_{2}$ flux inversions using satellite data, Atmos. Chem. Phys., 9, 7313-7323, doi:10.5194/acp-9-7313-2009, 2009.

Warner, J., Comer, M. M., Barnet, C. D., McMillan, W. Wolf, W., Maddy, W., E., and Sachse, G.: A comparison of satellite tropospheric carbon monoxide measurements from AIRS and MOPITT during INTEX-NA, J. Geophys. Res., 112, D12S17, doi:10.1029/2006JD007925, 2007.

Worden, H. M., Deeter, M. N., Edwards, D. P., Gille, J. C., Drummond, J. R., and Nédélec, P.: Observations of near-surface carbon monoxide from space using MOPITT multispectral retrievals, J. Geophys. Res., 115, D18314, doi:10.1029/2010JD014242, 2010.

Worden, J., Jiang, Z., Jones, D. B. A., Alvarado, M., Bowman, K., Frankenberg, C., Kort, E. A., Kulawik, S. S., Lee, M.-M., Liu, J.-J., Payne, V., Wecht, K., and Worden, H.: El Nino, The 2006 Indonesian Peat Fires, And The Distribution Of Atmospheric Methane, Geophys. Res. Lett., 40, 4938-4943, doi:10.1002/grl.50937, 2013.

Zhang, Q., Streets, D. G., Carmichael, G. R., He, K. B., Huo, H., Kannari, A., Klimont, Z., Park, I. S., Reddy, S., Fu, J. S., Chen, D., Duan, L., Lei, Y., Wang, L. T., and Yao, Z. L.: Asian emissions in 2006 for the NASA INTEX-B mission, Atmos. Chem. Phys., 9, 5131-5153, doi:10.5194/acp-9-5131-2009, 2009. 